\title{
A HIGH POWER FACTOR HYBRID THREE-PHASE RECTIFIER WITH REGENERATIVE CAPABILITY
}

\author{
Carlos Henrique Illa Font ${ }^{* *}$ and Ivo Barbi* \\ *Federal University of Santa Catarina - UFSC, Power Electronics Institute - INEP, Câmpus Reitor João David Ferreira Lima, \\ P. O. Box 5119, CEP 88040-970, Florianópolis-SC \\ ${ }^{* *}$ Federal University of Technology - Paraná - UTFPR, Dept. of Electronics Engineering, Câmpus Ponta Grossa, Av. Monteiro \\ Lobato, s/n km 04, CEP 84016-210, Ponta Grossa-PR \\ Email: illafont@,utfpr.edu.br, ivobarbi@,inep.ufsc.br
}

\begin{abstract}
This paper presents theoretical analysis and experimentation of a hybrid three-phase rectifier suitable for medium and high power applications. The hybrid rectifier is formed by the parallel connection of a threephase diode bridge rectifier cascaded by a DC-DC boost converter and a bidirectional boost-type three-phase PWM rectifier. The proposed rectifier is capable of providing sinusoidal input currents, DC output voltage control and regenerative power flow. Furthermore, the parallel association of different three-phase rectifier topologies provides power distribution, allowing the use of lower cost switches. The principle of operation, the theoretical analysis, the control scheme, simulation and experimental results from a $20-\mathrm{kW}$ prototype are presented. The prototype was designed for a $380 \mathrm{~V}$ of input voltage, $700 \mathrm{~V}$ of output voltage and switching frequency of $10 \mathrm{kHz}$.
\end{abstract}

Keywords - AC-DC Power Conversion, PFC, ThreePhase Rectifier, Hybrid Rectifier, AC Regenerative Drives.

\section{INTRODUCTION}

Nowadays, governments and international organizations have introduced the IEEE 519 and IEC 61000-3-2/61000-3-4 standards for limit the harmonic content of the currents drawn from the AC power line.

To address the problem a great number of new singlephase and three-phase rectifier topologies have been developed. In high power applications, where three-phase systems are required to avoid the system load unbalance, the search for three-phase rectifier topologies with high efficiency, high reliability, simple control scheme and high quality input currents were increased in the last decade.

Three-phase diode bridge rectifiers are commonly used as front-end converters due to their simplicity, reliability and low cost [1]. However, they do not meet the harmonic content imposed by the IEEE 519 and IEC 61000-3-2/610003-4 international standards.

The use of multi-pulse three-phase rectifiers achieve lower harmonic content of the input currents by cancellation of the harmonic components generated by each group of six-pulse diode bridge rectifier. Moreover, they keep the simplicity and reliability features. However, they are heavy, bulky and expensive [1-2].

Manuscript received 05/10/2011. Revised on 27/12/2011. Accepted for publication 13/01/2012 by recommendation of the Editor João Onofre Pereira Pinto.
Three-phase PWM rectifiers meet the international standards for harmonic current limit, providing sinusoidal input currents with low harmonic distortion. PWM rectifiers are more expensive and less reliable than diode bridge rectifiers. Besides, three-phase PWM rectifiers have limited power capability and present high cost in the range of medium and high power applications [3-5].

Direct parallel connection of three-phase PWM rectifiers achieves high power levels with the advantages of system redundancy, smaller current ripple, lower filtering effort and lower cost [6-11]. However, it causes current differences in each rectifier module and increases the active switch count.

In the last years, the search for rectifiers that comprise the better features of diode bridge rectifiers and the advantages of PWM rectifiers introduces a new class of three-phase rectifiers with low effect on the mains, the Hybrid Rectifiers [12-20].

The basic idea of the Hybrid Rectifiers is that they are generated by the parallel connection of different three-phase rectifier topologies. Moreover, the division of active power processed by each three-phase rectifier can be different, aiming the better utilization of each three-phase rectifier topology.

This paper proposes a hybrid three-phase rectifier with high power factor, DC output voltage control and regenerative capability. The rectifier employs a parallel connection of a three-phase diode bridge rectifier cascaded by a DC-DC boost converter and a bidirectional boost-type three-phase PWM rectifier.

First, the rectifier topology is presented in Section II. Section III of this paper presents the principle of operation and the modes of operation. The theoretical analysis of the hybrid rectifier is described in Section IV. Section V shows the control scheme. A simplified design example is presented in Section VI. Simulation results are presented in Section VII. Finally, the assembly of the prototype and the experimental results are presented in Section VIII.

\section{THE PROPOSED HYBRID RECTIFIER}

\section{A. Circuit Description}

The proposed hybrid three-phase rectifier is originated by the parallel connection of two topologies:

- the three-phase diode bridge rectifier cascaded by a DCDC boost converter (UR - unidirectional rectifier);

- the bidirectional boost-type three-phase PWM rectifier (BR - bidirectional rectifier).

A diagram of the circuit is presented in Figure 1. Split boost inductors and split boost diodes in the UR are 
necessary to avoid inappropriate current paths in the rectifier [21].

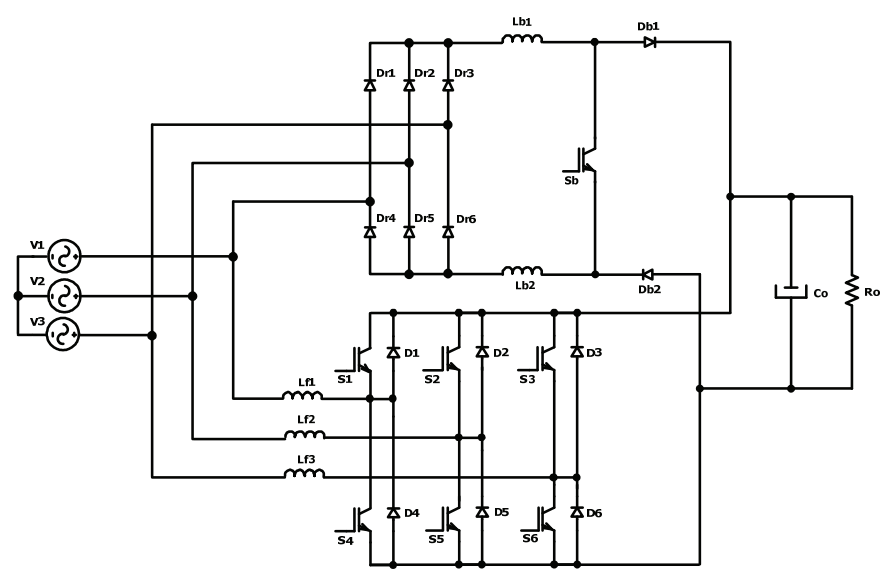

Fig. 1. Proposed hybrid three-phase rectifier.

The proposed hybrid three-phase rectifier can operate as regenerative rectifier, delivering the energy back from the $\mathrm{DC}$ side to the $\mathrm{AC}$ power mains.

\section{B. Operation as Rectifier}

During the operation as rectifier, both UR and BR are ON and the active power is shared between them. The rectifier presents sinusoidal input currents and DC output voltage control. A block diagram of this operation in presented in Figure 2.

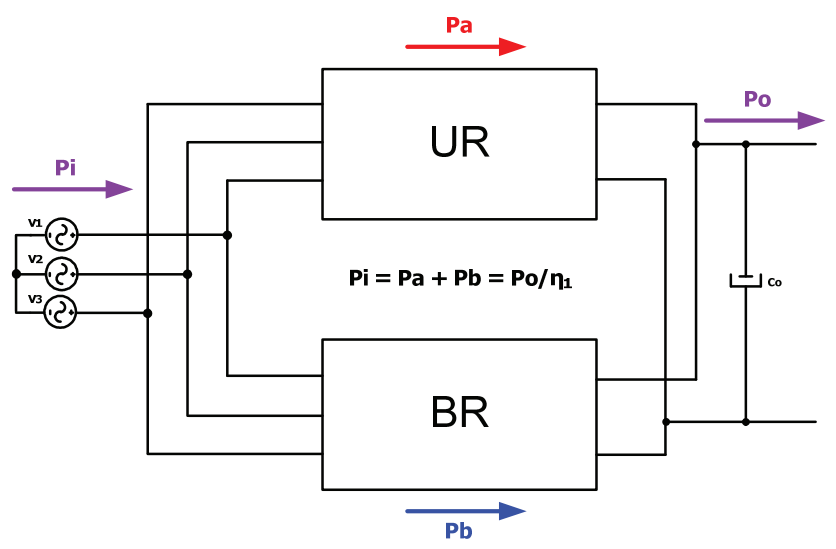

Fig. 2. Operation as rectifier.

\section{Operation as Inverter}

During the operation as inverter, BR is $\mathrm{ON}$ and then the power from de DC side is send back to the mains. The input currents are sinusoidal and the DC voltage is controlled. A block diagram of this operation in presented in Figure 3.

A comparison between this hybrid rectifier and the parallel connection of two bidirectional boost-type threephase PWM rectifiers [7-8] shows that the hybrid rectifier keeps the characteristics of regenerative power flow, high power factor and DC output voltage control. It also preserves the advantages of system redundancy, lower filter effort and smaller current ripple, with a reduction in the number of active switches from 12 to 7, e. g., with a reduction of $40 \%$ in active switch count.

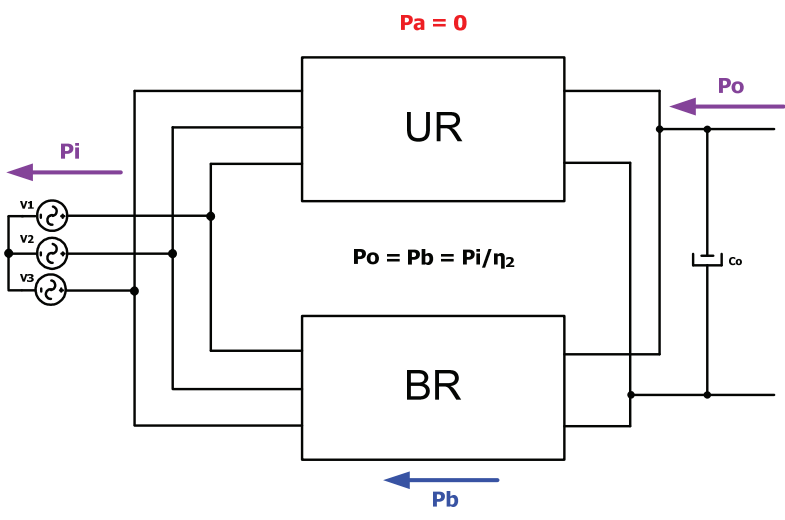

Fig. 3. Operation as inverter.

\section{PRINCIPLE OF OPERATION}

\section{A. Basic Input Currents Waveforms}

The principle of operation can be explained by the analysis of the input currents of UR and BR. The input currents and the output currents in the proposed bidirectional hybrid three-phase rectifier are identified in Figure 4.

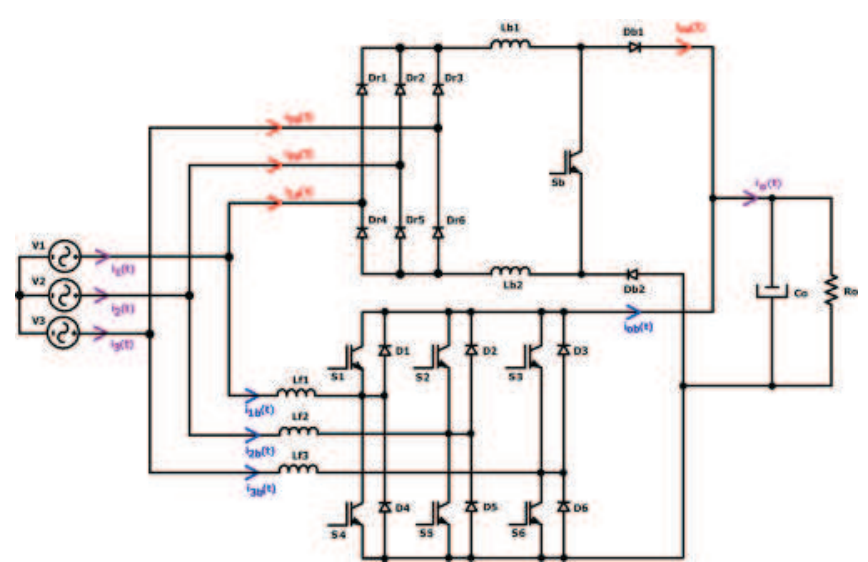

Fig. 4. Currents in the proposed bidirectional hybrid three-phase rectifier.

The line currents i1, i2 and i3 (hybrid rectifier input currents) are obtained by the sum of currents i1a, i2a and i3a (UR input currents) and currents $\mathrm{i} 1 \mathrm{~b}, \mathrm{i} 2 \mathrm{~b}$ and $\mathrm{i} 3 \mathrm{~b}$ (BR input currents), respectively. Similarly, at the output, the load current io is the sum of currents ioa and iob.

To achieve high power factor, the line currents i1, i2 and i3 must be sinusoidal and without displacement factor. This way, the currents $i 1 \mathrm{a}, \mathrm{i} 2 \mathrm{a}$ and $\mathrm{i} 3 \mathrm{a}$ and currents $\mathrm{i} 1 \mathrm{~b}, \mathrm{i} 2 \mathrm{~b}$ and $\mathrm{i} 3 \mathrm{~b}$ will be controlled to provide the line currents with a sinusoidal shape.

The shape of the currents ila, i2a and i3a are imposed by the diode bridge of UR and, by the control of the DC-DC Boost inductor current, the amplitude of these currents can be controlled. The DC-DC Boost converter must be operating in Continuous Conduction Mode and Boost inductor current must be following a constant reference current. Therefore, the diode bridge rectifier keeps its characteristic of low frequency commutation. 
The currents $\mathrm{i} 1 \mathrm{~b}, \mathrm{i} 2 \mathrm{~b}$ and $\mathrm{i} 3 \mathrm{~b}$ are controlled to follow a desired reference, so that the sum of these currents with the currents i1a, i2a and i3a results in sinusoidal input currents.

The power level processed by each rectifier can be related with the maximum value of the input currents. For a rated output power, theoretically, any power sharing can be performed by the rectifier and in all cases, hybrid rectifier input currents will present sinusoidal shape. Therefore, it is interesting that the UR processes the greatest part of the output power.

Each combination between the powers processed for each rectifier represents a specific mode of operation. Figure 5 shows the ideal currents waveforms for two different modes of operation. The first operation mode, called operation mode 1 , is related with the situation where UR supplies the output rated power. Thus, the BR processes just the energy necessary to achieve high power factor at the input. For this situation, the current waveforms are presented in Figure 5 a), Figure $5 \mathrm{~b}$ ) and Figure $5 \mathrm{c}$ ).
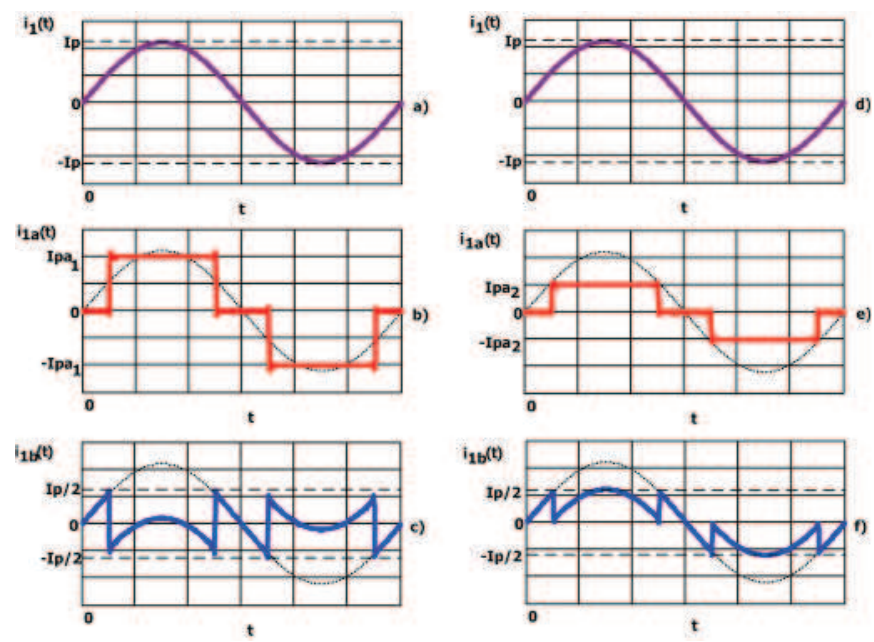

Fig. 5. The ideal currents waveforms for different modes of operation: a) line current i1, b) current ila and c) current ilb for operation mode 1 ; d) line current i1, e) current ila and f) current i1b for operation mode 2 .

The second operation mode, called operation mode 2 , is related with the situation where each rectifier supplies a half of the output power. In this case, the current waveforms are presented in Figure 5 d), Figure 5 e) and Figure 5 f).

\section{B. Basic Equations}

For describing the basic relations of the hybrid rectifier system, the analysis is limited to the fundamentals of the system quantities on the AC side.

Assuming the phase 1 as reference, the instantaneous power in phase 1 is presented by (1).

$$
p_{1}(t)=v_{1}(t) \cdot i_{1}(t)
$$

where:

p1(t) : instantaneous power in phase 1 ;

$\mathrm{v} 1(\mathrm{t})$ : instantaneous mains phase voltage in phase 1 ;

i1(t) : instantaneous mains current in phase 1 .

The mains current i1 is the sum of currents ila and ilb. It yields to:

$$
i_{1}(t)=i_{1 a}(t)+i_{1 b}(t)
$$

Substituting (2) in (1) leads to (3).

$$
p_{1}(t)=v_{1}(t) \cdot\left[i_{1 a}(t)+i_{1 b}(t)\right]
$$

Defining $\mathrm{pla}$ as the instantaneous power processed by UR and $\mathrm{plb}$ as the instantaneous power processed by BR, it leads to:

$$
p_{1}(t)=p_{1 a}(t)+p_{1 b}(t)
$$

where:

$$
\begin{aligned}
& p_{1 a}(t)=v_{1}(t) \cdot i_{1 a}(t) \\
& p_{1 b}(t)=v_{1}(t) \cdot i_{1 b}(t)
\end{aligned}
$$

Therefore, the active power processed by UR and BR are presented in (7) and (8), respectively.

$$
\begin{gathered}
P_{1 a}=\frac{1}{T} \int_{0}^{T} p_{1 a}(t)=\frac{\sqrt{3} \cdot V_{p} \cdot I_{p a}}{\pi} \\
P_{1 b}=\frac{1}{T} \int_{0}^{T} p_{1 b}(t)=V_{p} \cdot\left(\frac{I_{p}}{2}-\frac{\sqrt{3}}{\pi} \cdot I_{p a}\right)
\end{gathered}
$$

where:

Vp: peak value of mains phase voltage;

Ip: peak value of mains current;

Ipa: maximum current value at the input of the UR.

The expressions (7) and (8) show that the active power processed by each rectifier is a function of the mains peak voltage, the mains peak current and the maximum current at the input of the UR.

In a similar manner, the magnitudes of apparent powers at the inputs of each rectifier can be obtained. The magnitude of the apparent power processed by UR and BR are presented in (9) and (10), respectively.

$$
\begin{gathered}
S_{1 a}=\frac{\sqrt{3} \cdot V_{p} \cdot I_{p a}}{3} \\
S_{1 b}=V_{p} \cdot I_{p} \cdot \sqrt{\frac{1}{4}-\frac{\sqrt{3}}{\pi} \cdot \frac{I_{p a}}{I_{p}}+\frac{1}{3} \cdot \frac{I_{p a}{ }^{2}}{I_{p}{ }^{2}}}
\end{gathered}
$$

\section{THEORETICAL ANALYSIS}

\section{A. Active Power and Apparent Power Sharing}

The rated power processed by each rectifier can be related with the maximum current values of currents i1, ila and ilb, for phase 1 for instance.

Each power sharing defines an operation mode. The aim of the analysis presented here is to identify which are the operation modes with improved performance.

Assuming the phase 1 as reference, the active power P1 is the average value of instantaneous power $\mathrm{p} 1$. It is given by (11).

$$
P_{1}=\frac{1}{T} \int_{0}^{T} p_{1}(t)=\frac{V_{p} \cdot I_{p}}{2}
$$

The relationships between the active power processed by each rectifier and the input active power are obtained from (7), (8) and (11). They are presented in (12) and (13). 


$$
\begin{gathered}
\frac{P_{1 a}}{P_{1}}=\frac{2 \cdot \sqrt{3}}{\pi} \cdot \frac{I_{p a}}{I_{p}} \\
\frac{P_{1 b}}{P_{1}}=1-\frac{2 \cdot \sqrt{3}}{\pi} \cdot \frac{I_{p a}}{I_{p}}
\end{gathered}
$$

The dependency of the power processed by each rectifier in terms of the mains peak current and maximum value of the current in the input of UR is demonstrated in (12) and (13).

The magnitude of the input apparent power of each rectifier can be related with the currents in a similar manner. The input apparent power of the hybrid rectifier is given by (14), where, ideally, it is the same value of the active power, featuring unity power factor.

$$
S_{1}=\frac{V_{p} \cdot I_{p}}{2}
$$

The relationships between the magnitudes of apparent power processed by each rectifier and the input apparent power are obtained from (9), (10) and (14). They are presented in (15) and (16).

$$
\begin{gathered}
\frac{S_{1 a}}{S_{1}}=\frac{2 \cdot \sqrt{3}}{3} \cdot \frac{I_{p a}}{I_{p}} \\
\frac{S_{1 b}}{S_{1}}=\sqrt{1-\frac{4 \cdot \sqrt{3}}{\pi} \cdot \frac{I_{p a}}{I_{p}}+\frac{4}{3} \cdot \frac{I_{p a}{ }^{2}}{I_{p}{ }^{2}}}
\end{gathered}
$$

For the operation mode 1, where UR supplies the output rated power, the relations for the active powers are:

$$
\left\{\begin{array}{l}
P_{1 a}=P_{1} \\
P_{1 b}=0
\end{array}\right.
$$

Therefore, the value of relation between the currents can be obtained by (12) or (13). With this value, (15) and (16) solve the values of the magnitudes of apparent power. Table I summarizes these correspondent values.

TABLE I

The values of relations between the peak currents and the magnitudes of apparent power

\begin{tabular}{ccc}
\hline & \multicolumn{2}{c}{ Operation Mode } \\
\cline { 2 - 3 } & 1 & 2 \\
\hline $\mathbf{I}_{\mathbf{p a}} / \mathbf{I}_{\mathbf{p}}$ & 0.91 & 0.45 \\
\hline $\mathbf{S}_{\mathbf{1 a}} / \mathbf{S}_{\mathbf{1}}$ & 1.05 & 0.52 \\
\hline $\mathbf{S}_{\mathbf{1 b}} / \mathbf{S}_{\mathbf{1}}$ & 0.31 & 0.52 \\
\hline
\end{tabular}

In the operation mode 2, each rectifier processes a half of the output power, thus the relations for the active powers are:

$$
\left\{\begin{array}{l}
P_{1 a}=\frac{P_{1}}{2} \\
P_{1 b}=\frac{P_{1}}{2}
\end{array}\right.
$$

Table I also presents the values of relation between the currents and the magnitudes of apparent power for the operation mode 2 .
Equation (19) defines the auxiliary variable $\alpha$, where $0 \leq \alpha$ $\leq 1$. The parameter $\alpha$ represents the variation of maximum value Ipa for the same value of mains peak current Ip.

$$
\alpha=\frac{I_{p a}}{I_{p}}
$$

Rewriting (12), (13), (15) and (16) as a function of $\alpha$ yields to:

$$
\begin{gathered}
\frac{P_{1 a}}{P_{1}}(\alpha)=\frac{2 \cdot \sqrt{3}}{\pi} \cdot \alpha \\
\frac{P_{1 b}}{P_{1}}(\alpha)=1-\frac{2 \cdot \sqrt{3}}{\pi} \cdot \alpha \\
\frac{S_{1 a}}{S_{1}}(\alpha)=\frac{2 \cdot \sqrt{3}}{3} \cdot \alpha \\
\frac{S_{1 b}}{S_{1}}(\alpha)=\sqrt{1-\frac{4 \cdot \sqrt{3}}{\pi} \cdot \alpha+\frac{4}{3} \cdot \alpha^{2}}
\end{gathered}
$$

The curves presented in Figure 6 were obtained by (20) and (21). They show the behavior of the active power processed for each rectifier for different operation modes. Note that the curves are parameterized by the input active power P1.

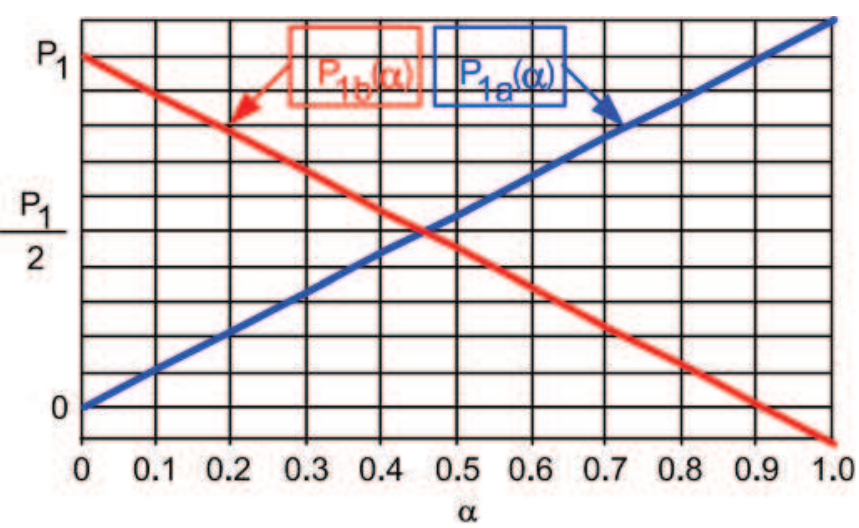

Fig. 6. Curves for the active power processed by each rectifier.

It is interesting to observe that, in the operation mode where $I_{p a}=I_{p}$, BR acts as a load for UR. In fact, in this case the active power $\mathrm{P} 1 \mathrm{~b}$ is negative and the relation obtained is $P_{1 b}=-0.103 P_{1}$. This situation does not have any experimental interest and it must be avoided.

The results presented in Table I for operation modes 1 and 2 can also be verified in Figure 6.

The magnitudes of apparent power processed by each rectifier, presented in (22) and (23), can be plotted for every operation mode, as shown in Figure 7. Note that the curves are parameterized by the magnitude of input apparent power S1.

Figure 7 shows the curves for the magnitudes of apparent power processed by each rectifier. The region of operation where $0.75 \leq \alpha \leq 0.91$ is interesting for the BR operation, because its apparent power processed is minimized. 


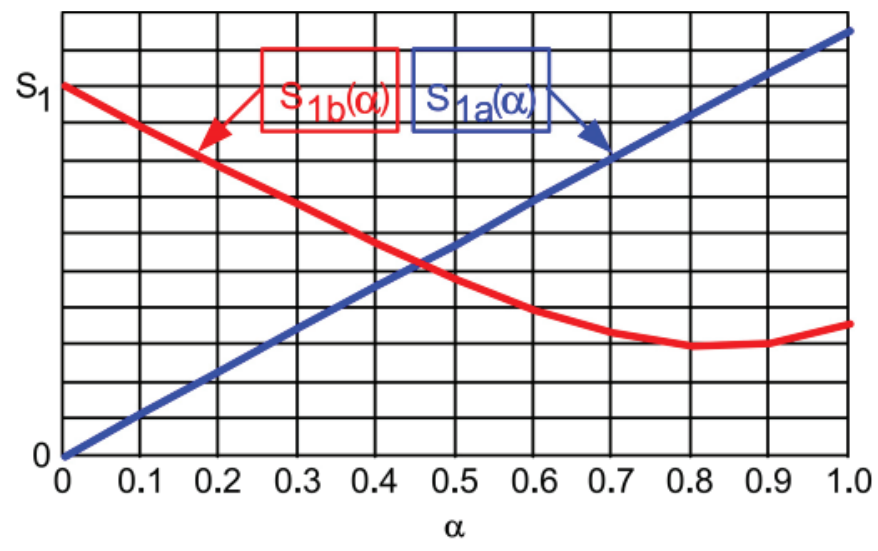

Fig. 7. Curves for the magnitudes of apparent power processed by each rectifier.

The curves presented in Figure 6 and Figure 7 shows a region of operation with improved performance. The region among the interval $0.75 \leq \alpha \leq 0.91$ minimizes the active power and the apparent power processed by BR and maximizes the active power processed by UR.

\section{B. Reactive Components Ratings}

To design the hybrid rectifier the reactive components current and voltage ratings are required. The equations are obtained by restricting the analysis to the positive half wave of a mains phase voltage where $60^{\circ} \leq \omega \mathrm{t} \leq 90^{\circ}$, since the hybrid rectifier has a symmetrical behavior in each $30^{\circ}$ of the mains period.

1) Inductances of the UR (Lb1 and Lb2)

The inductances of the UR can be calculated by (24).

$$
\mathrm{L}_{\mathrm{b}}=\frac{3}{2} \cdot \frac{\mathrm{V}_{\mathrm{p}}}{\Delta \mathrm{I}_{\mathrm{Lb}} \cdot \mathrm{f}_{\mathrm{s}}} \cdot\left(1-\frac{3 \cdot \mathrm{V}_{\mathrm{p}}}{2 \cdot \mathrm{V}_{\mathrm{o}}}\right)
$$

where:

Vp: peak value of mains phase voltage;

Vo: average output voltage;

fs: switching frequency;

$\triangle I L b$ : UR's inductor current ripple.

Since the inductors at UR are split, each inductor has the half of the total inductance Lb, e.g.:

$$
\mathrm{L}_{\mathrm{b} 1}=\mathrm{L}_{\mathrm{b} 2}=\frac{\mathrm{L}_{\mathrm{b}}}{2}
$$

The values of inductor peak current and the inductor RMS current are given by (26) and (27), respectively.

$$
\begin{gathered}
\mathrm{I}_{\mathrm{Lb}_{-} \mathrm{pk}}=\mathrm{I}_{\mathrm{pa}}+\frac{\Delta \mathrm{I}_{\mathrm{Lb}}}{2} \\
\mathrm{I}_{\mathrm{Lb} \_ \text {RMS }}=\mathrm{I}_{\mathrm{pa}}
\end{gathered}
$$

2) Inductances of the BR (Lf1, Lf2 and Lf3)

The inductances of the BR can be calculated by (28).

$$
\mathrm{L}_{\mathrm{f}}=\frac{\mathrm{V}_{\mathrm{p}}}{\Delta \mathrm{I}_{\mathrm{Lf}} \cdot \mathrm{f}_{\mathrm{s}}}\left(1-\frac{3 \cdot \mathrm{V}_{\mathrm{p}}}{2 \cdot \mathrm{V}_{\mathrm{o}}}\right)
$$

where:

$\triangle \mathrm{ILf}: \mathrm{BR}$ 's inductor current ripple.
The values of inductor peak current and the inductor RMS current are given by (29) and (30), respectively.

$$
\begin{gathered}
I_{L_{-} \text {pk }}=\frac{I_{p}}{2} \\
I_{L_{-} R M S}=\sqrt{\frac{I_{p}{ }^{2}}{2}-\frac{2 \cdot \sqrt{3}}{\pi} \cdot I_{p} \cdot I_{p a}+\frac{2}{3} \cdot I_{p a}{ }^{2}}
\end{gathered}
$$

3) Output Capacitor (Co)

The values of output capacitor peak current and the RMS current are given by (31) and (32), respectively.

$$
\begin{aligned}
& \mathrm{I}_{\mathrm{Co}_{-} \mathrm{pk}}=\mathrm{I}_{\mathrm{o}}+\mathrm{I}_{\mathrm{pa}}-\frac{\mathrm{I}_{\mathrm{p}}}{2} \\
& \mathrm{I}_{\mathrm{o}}^{2}+\frac{5 \cdot \sqrt{3}}{2 \cdot \pi} \cdot \frac{\mathrm{V}_{\mathrm{p}}}{\mathrm{V}_{\mathrm{o}}} \cdot \mathrm{I}_{\mathrm{p}}^{2}+\left(1-\frac{3 \cdot \sqrt{3}}{\pi} \cdot \frac{\mathrm{V}_{\mathrm{p}}}{\mathrm{V}_{\mathrm{o}}}\right) \cdot \mathrm{I}_{\mathrm{pa}}^{2}+ \\
& \mathrm{I}_{\mathrm{CO} \_\mathrm{R} M S}=\left\{\begin{array}{l}
+\left(\frac{3 \cdot \sqrt{3}}{2 \cdot \pi} \cdot \frac{\mathrm{V}_{\mathrm{p}}}{\mathrm{V}_{\mathrm{o}}}-\frac{3 \cdot \sqrt{3}}{2 \cdot \pi}+\frac{1}{2} \cdot \frac{\mathrm{V}_{\mathrm{p}}}{\mathrm{V}_{\mathrm{o}}}\right) \mathrm{I}_{\mathrm{p}} \cdot \mathrm{I}_{\mathrm{pa}}- \\
-3 \cdot \frac{\mathrm{V}_{\mathrm{p}}}{\mathrm{V}_{\mathrm{o}}} \cdot \mathrm{I}_{\mathrm{p}} \cdot \mathrm{I}_{\mathrm{o}}
\end{array}\right.
\end{aligned}
$$

where:

Io: average output current.

The value of maximum output capacitor voltage is obtained by (33).

$$
\mathrm{V}_{\mathrm{Co} \_\mathrm{pk}}=\mathrm{V}_{\mathrm{o}}
$$

\section{CONTROL STRATEGY}

The control scheme of the hybrid rectifier is shown in Figure 8. It is composed by four current control loops and a voltage control loop, based on the analog multiplier approach.

The gains and the variables presented in Figure 8 are described as follow:

- kI1, kI2, kI3 and kILb: current sensors gains;

- kVi: mains voltage gains;

- $\mathrm{kVo}$ : output voltage gain;

- $\mathrm{k} 1$ and $\mathrm{k} 2$ : active power sharing gains;

- $\mathrm{km} 1$ and $\mathrm{km} 2$ : multiplier gains;

- $\mathrm{kCC}$ : DC voltage proportional to mains voltage gain;

- kff: feedforward loop gain;

- VRef: system reference voltage;

- V1ref, V2ref and V3ref: sinusoidal reference voltages;

- VccRef: DC voltage proportional to mains voltages;

- Vff: feedforward voltage;

- HI1(s), HI2(s), HI3(s) and HILb(s): current controllers;

- $\mathrm{Hv}(\mathrm{s})$ : output voltage controller;

- PWM1, PWM2, PWM3 and PWMb: PWM modulators.

The voltage control loop provides DC output voltage regulation and the references for the current control loops.

The current control loops provide high power factor. In the case of the hybrid rectifier, where the mains currents are the sum of the input currents of UR and BR, there are two different current control loops. 


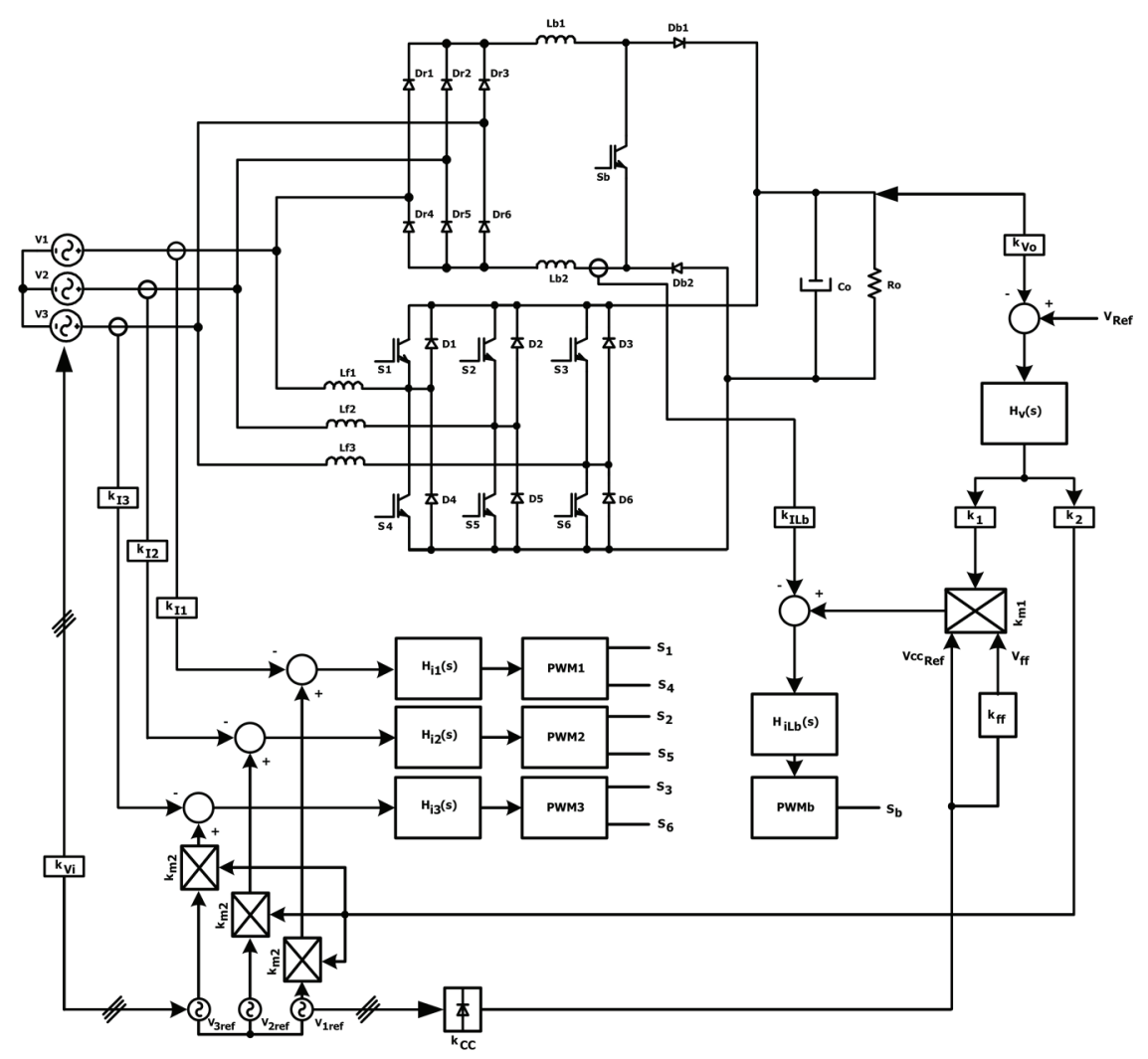

Fig. 8. The control scheme.

The UR current control loop is realized by the sensing and control of the current in inductor Lb2. This current must follow a DC reference proportional to the mains voltage. Since the UR input currents waveforms are imposed by the low frequency commutation of the diode bridge, this current control loop will control the maximum value of the UR input currents (Ipa). Thus, the active power processed by UR is set up, according to equation (7).

The BR input currents control is implemented by three control loops. These currents must follow a desired reference which will produce currents waveforms in such a way that, summed with the UR input currents, will result in mains sinusoidal currents. The sensing and control of the BR input currents (e.g., the currents in inductors Lf1, Lf2 and Lf3) require a non-sinusoidal current reference. Thus, the BR input currents are sensed and controlled indirectly by the mains input currents, which must follow sinusoidal references.

In order to avoid any interactions between the different currents control loops, the dynamic response of the UR current control loop is designed to be slower than the dynamic response of the BR currents control loops. This consideration will not affect the dynamic response of the overall hybrid rectifier because the UR current control loop must follow a DC current reference.

Finally, for the active power sharing, the gains $\mathrm{k} 1$ and $\mathrm{k} 2$ must be determined as a function of the power processed by each rectifier or as a function of the mains peak current (Ip) and the maximum value of the current in the UR input (Ipa), according to expressions (7) and (8).
The analysis of the block diagrams presented in the control strategy of Figure 8 results in:

$$
\frac{\mathrm{k}_{1}}{\mathrm{k}_{2}}=\frac{\mathrm{I}_{\mathrm{pa}}}{\mathrm{I}_{\mathrm{p}}} \cdot \frac{0,9 \cdot \mathrm{k}_{\mathrm{m} 1} \cdot \mathrm{k}_{\mathrm{m} 2} \cdot \mathrm{k}_{\mathrm{ILb}} \cdot \mathrm{k}_{\mathrm{CC}} \cdot \mathrm{k}_{\mathrm{ff}}^{2} \cdot \mathrm{k}_{\mathrm{Vi}}{ }^{2} \cdot \mathrm{V}_{\mathrm{p}}^{2}}{\sqrt{2} \cdot \mathrm{k}_{\mathrm{I} 1}}
$$

The dynamic model and the control design of the hybrid rectifier will be omitted here for the sake of brevity.

\section{DESIGN EXAMPLE}

The design example is based on the specifications presented in Table II. The same specifications will be used for the numeric simulation and the assembling of the prototype.

TABLE II

Design specifications

\begin{tabular}{cc}
\hline RMS Mains Line Voltage & $380 \mathrm{~V}$ \\
\hline Mains Frequency & $60 \mathrm{~Hz}$ \\
\hline Output Voltage & $700 \mathrm{~V}$ \\
\hline Output Power & $20 \mathrm{~kW}$ \\
\hline Switching Frequency & $10 \mathrm{kHz}$ \\
\hline
\end{tabular}

The operation mode where $\alpha=0.75$ was selected. In this case, the active power processed by UR is about $80 \%$ of the rated power and the power processed by BR is about $20 \%$ of the rated power. 


\section{A. Active Power}

For the operation mode where $\alpha=0.75$, the active power processed in each rectifier is:

$$
\begin{gathered}
P_{1 a} \cong 5.50 \mathrm{~kW} \\
P_{1 b} \cong 1.17 \mathrm{~kW}
\end{gathered}
$$

Thus, the active power processed by UR is about $16.5 \mathrm{~kW}$ and the active power processed by BR is about $3.5 \mathrm{~kW}$.

\section{B. Apparent Power}

For the operation mode where $\alpha=0.75$, the magnitude of the apparent power processed in each rectifier is:

$$
\begin{aligned}
& S_{1 a} \cong 5.77 \mathrm{VA} \\
& S_{1 b} \cong 2.07 \mathrm{VA}
\end{aligned}
$$

\section{Inductances of the UR (Lb1 and Lb2)}

The inductances of the UR can be calculated by (39) and (40), for a current ripple $\Delta \mathrm{I}_{\mathrm{Lb}}=3.4 \mathrm{~A}$.

$$
\begin{gathered}
\mathrm{L}_{\mathrm{b}}=4.60 \mathrm{mH} \\
\mathrm{L}_{\mathrm{b} 1}=\mathrm{L}_{\mathrm{b} 2}=2.30 \mathrm{mH}
\end{gathered}
$$

The values of inductor peak current and the inductor RMS current are given by (41) and (42), respectively.

$$
\begin{gathered}
I_{L_{-} b_{k}}=33.90 \mathrm{~A} \\
\mathrm{I}_{\mathrm{Lb}_{-} \mathrm{RMS}}=32.20 \mathrm{~A}
\end{gathered}
$$

\section{Inductances of the BR (Lf1, Lf2 and Lf3)}

The inductances of the BR can be calculated by (43), for a current ripple $\Delta \mathrm{I}_{\mathrm{Lf}}=4.2 \mathrm{~A}$.

$$
\mathrm{L}_{\mathrm{f}}=2.40 \mathrm{mH}
$$

The values of inductor peak current and the inductor RMS current are given by (44) and (45), respectively.

$$
\begin{aligned}
& I_{\text {Lf_pk }}=21.40 \mathrm{~A} \\
& I_{\text {Lf_RMS }}=9.35 \mathrm{~A}
\end{aligned}
$$

\section{E. Output Capacitor (Co)}

The values of output capacitor peak current and the output capacitor RMS current are calculated by (46) and (47), respectively.

$$
\begin{gathered}
\mathrm{I}_{\mathrm{Co} \_p k}=39.40 \mathrm{~A} \\
\mathrm{I}_{\mathrm{CO} \_ \text {RMS }}=16.13 \mathrm{~A}
\end{gathered}
$$
(48).

The maximum output capacitor voltage is obtained by

$$
\mathrm{V}_{\mathrm{Co} \_\mathrm{pk}}=700.00 \mathrm{~V}
$$

\section{SIMULATION RESULTS}

To confirm the operation of the hybrid rectifier, a numeric simulation has been performed with the specifications of Table II and using PSIM software, version 9.0.4.
In the simulation, the hybrid rectifier is operating in closed-loop voltage and current control. A bidirectional current source was used as a load for testing both operations as a rectifier and as an inverter.

Figure 9 presents the output current and the output voltage of the hybrid rectifier. During the interval $(0.5 \mathrm{~s} ; 1.0 \mathrm{~s})$ the hybrid converter is operating as a rectifier and during the interval $(1.1 \mathrm{~s} ; 2.0 \mathrm{~s})$ it is operating as an inverter. As may be seen the output voltage is controlled during the transient interval $(1.0 \mathrm{~s} ; 1.1 \mathrm{~s})$.

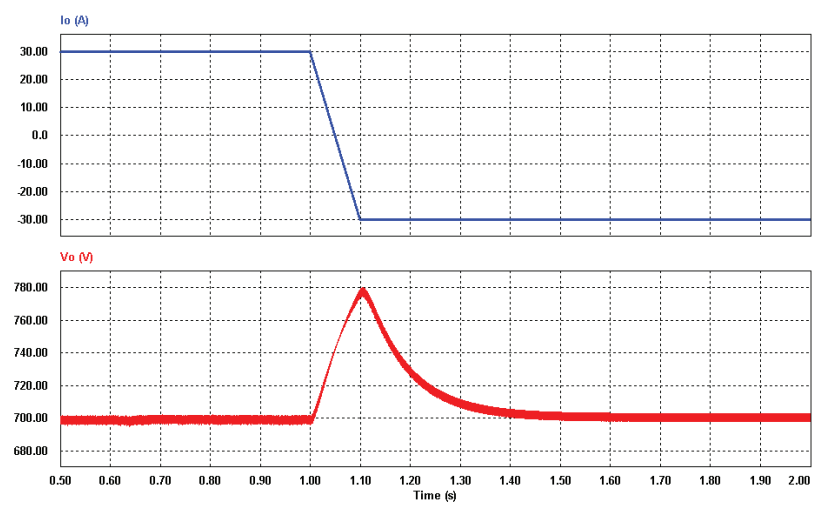

Fig. 9. Output current and output voltage.

The mains phase voltage and the mains current in phase 1 are presented in Figure 10. It is observed that during the rectifier operation, the current is sinusoidal and without displacement factor, providing high power factor. During the operation as an inverter, only BR is sending back the load energy to the mains as may be observed by the phase opposition of the mains current in relation to the mains voltage.

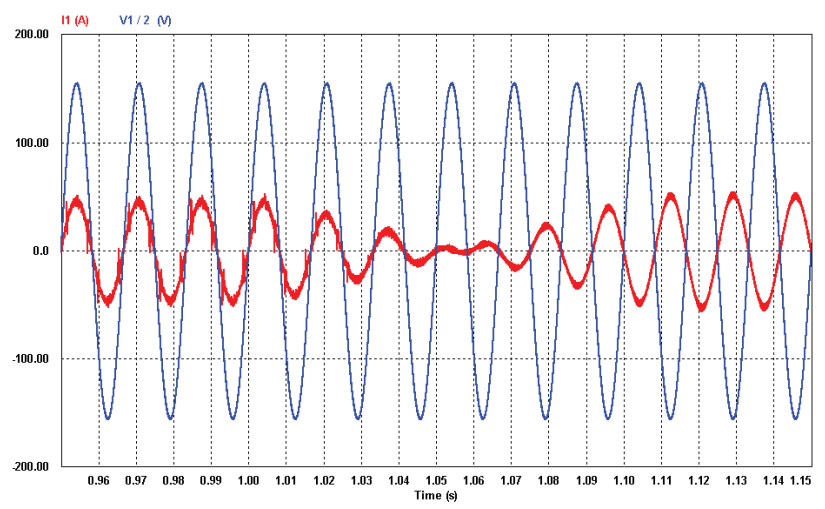

Fig. 10. Mains phase voltage and mains current in phase 1.

\section{EXPERIMENTAL EVALUATION}

\section{A. Prototype Implementation}

A prototype of the proposed three-phase hybrid rectifier was implemented in order to validate the theoretical analysis. A picture of the prototype can be seen in Figure 11 and the components of the prototype are shown in Table III. 


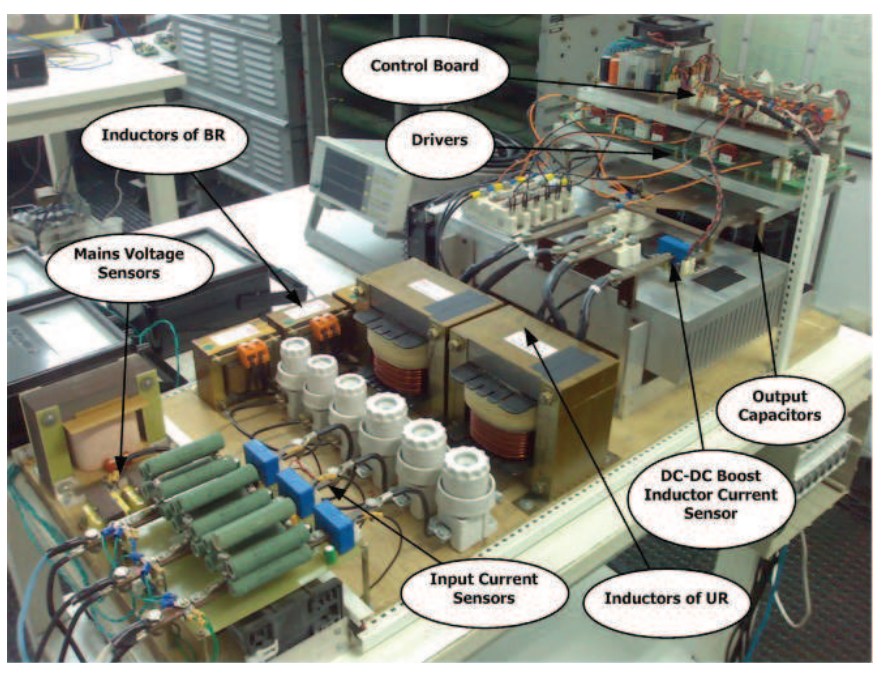

Fig. 11. Picture of the prototype.

TABLE III

Components of the prototype

\begin{tabular}{cc}
\hline Dr1, Dr2, Dr3, Dr4, Dr5 and Dr6 & SKD82/12 \\
\hline Sb and Db1 & SKM50GAL123D \\
\hline Db2 & HFA80FA120 \\
\hline $\begin{array}{c}\text { S1, S2, S3, S4, S5, S6, D1, D2, } \\
\text { D3, D4, D5 and D6 }\end{array}$ & SKM22GD123D \\
\hline Lb1 and Lb2 & $2.3 \mathrm{mH} / 40 \mathrm{~A}$ \\
\hline Lf1, Lf2 and Lf3 & $2.4 \mathrm{mH} / 15 \mathrm{~A}$ \\
\hline Co & $8 \times 2200 \mathrm{uF} / 450 \mathrm{~V}$ \\
\hline Current Sensors & LA55-P \\
\hline Output Voltage Sensor & LV25-P SP8 \\
\hline Mains Voltage Sensor & $3 \times 1 \mathrm{p} \Delta$ - $\Delta$ Signal Transformer \\
\hline
\end{tabular}

The control circuit was implemented with analog components, using the integrated circuit UC3854B and the four-quadrant multipliers MPY634. The synchronized PWM modulation was realized with the UC3854B internal modulator and a common triangular carrier signal.

\section{B. Experimental Results}

Figure 12 shows the input currents i1, i2, i3 and the output voltage. The input currents have sinusoidal shape and total harmonic distortion is about $6.5 \%$. The output voltage average value is about $700 \mathrm{~V}$.

Figure 13 shows the input current i1, the current ila, the current $\mathrm{ilb}$ and the output voltage. The input current i1 is the sum of currents ila and ilb.

Figure 14 shows the input currents and the output voltage during the start-up transient. Three different stages can be identified during start-up transient: i) the first stage is the inrush stage; ii) in the second stage the hybrid rectifier is operating as a diode bridge rectifier; iii) the third stage is the PFC stage with soft-start operation. The start-up was realized in light load condition with approximately $4 \mathrm{~kW}$ of output power.

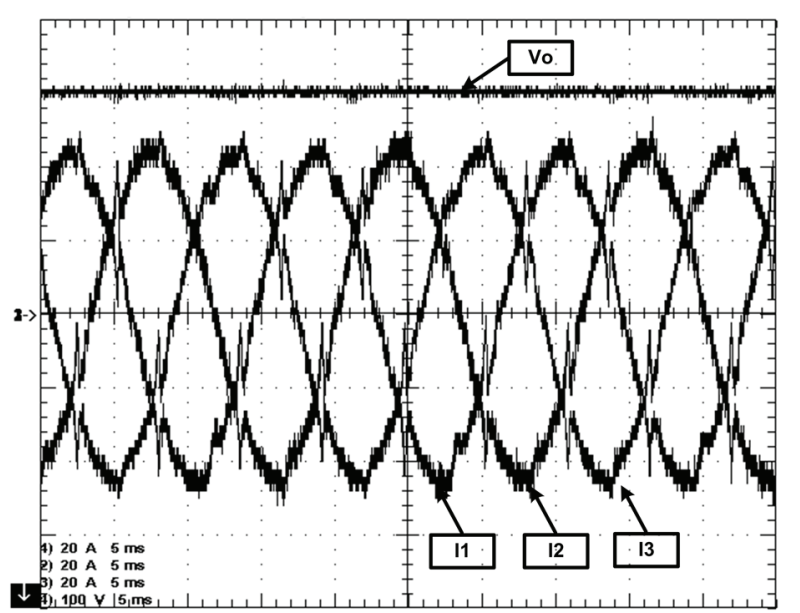

Fig. 12. Input current i1 (Ch1: 20A/div), input current i2 (Ch2: 20A/div), input current i3 (Ch3: 20A/div) and the output voltage (Ch4: 100V/div). Time (5ms/div).

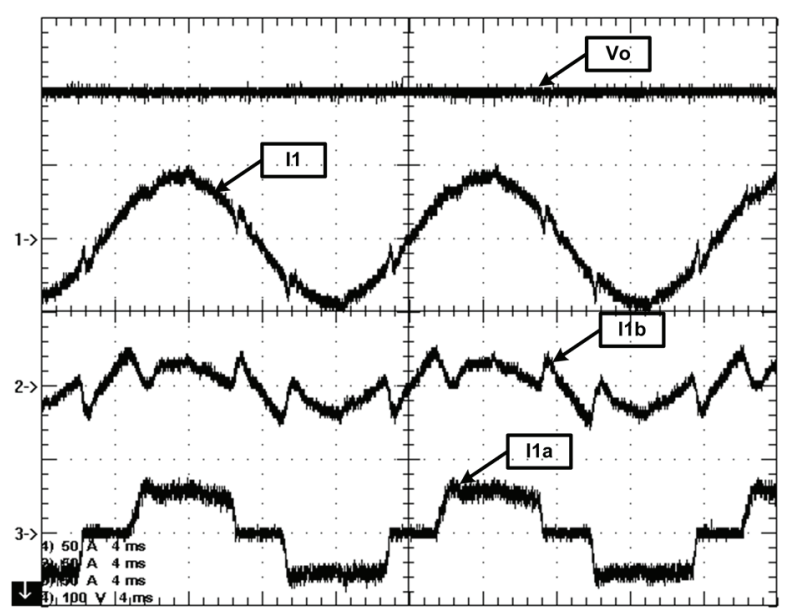

Fig. 13. Input current i1 (Ch1: 50A/div), current ilb (Ch2: $50 \mathrm{~A} / \mathrm{div})$, current ila (Ch3: $50 \mathrm{~A} / \mathrm{div})$ and the output voltage $(\mathrm{Ch} 4$ : $100 \mathrm{~V} / \mathrm{div})$. Time (4ms/div).

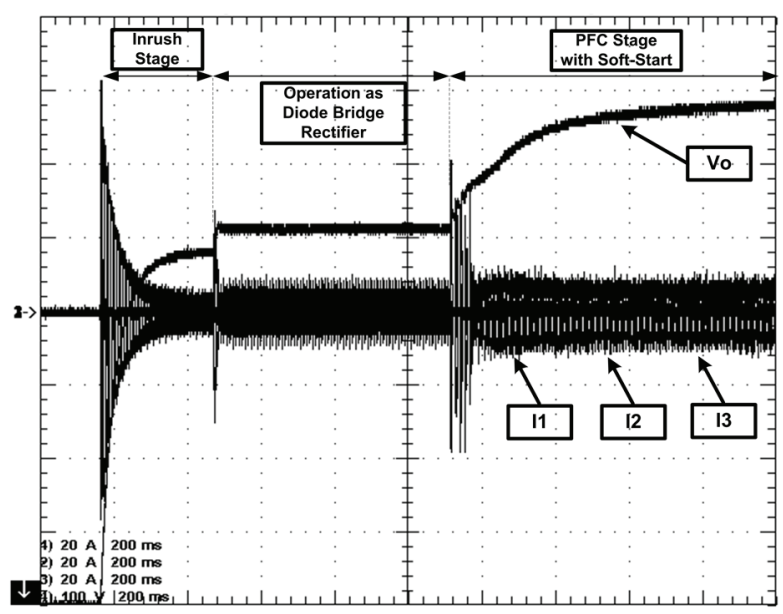

Fig. 14. Input current i1 (Ch1: 20A/div), input current i2 (Ch2: 20A/div), input current i3 (Ch3: 20A/div) and the output voltage (Ch4: 100V/div). Time (200ms/div). 
Figure 15 shows the input currents and the output voltage during a positive step load transient. As may be seen the output voltage is controlled and there are no spikes in input currents, which follow a sinusoidal reference.

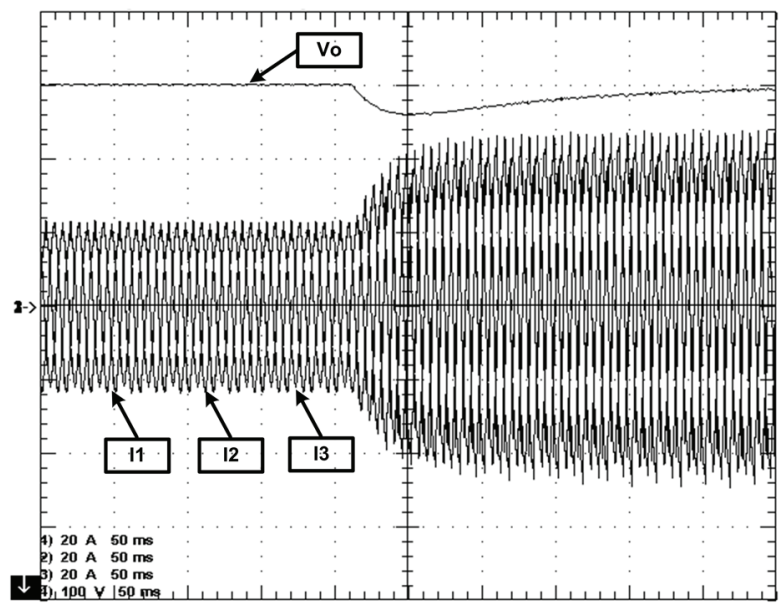

Fig. 15. Input current i1 (Ch1: 20A/div), input current i2 (Ch2: 20A/div), input current i3 (Ch3: 20A/div) and the output voltage (Ch4: 100V/div). Time (50ms/div).

Figure 16 shows the experimental efficiency of the prototype. The measurement includes the auxiliary power supply consumption. Note that the hybrid rectifier is operating without any soft commutation technique.

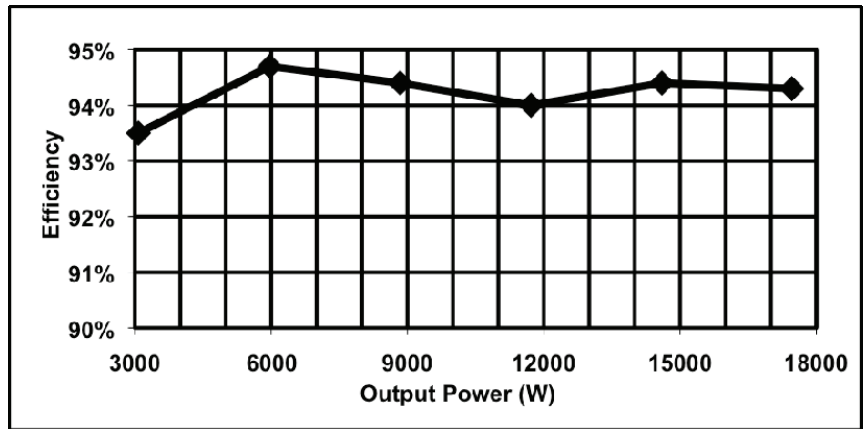

Fig. 16. Measured efficiency of the prototype for various output power values.

\section{CONCLUSIONS}

This paper presents a topology of hybrid three-phase rectifier suitable for medium and high power applications. The hybrid rectifier is composed by the parallel association of two different rectifier topologies: the three-phase diode bridge rectifier cascaded by a DC-DC boost converter (UR unidirectional rectifier) and the bidirectional boost-type three-phase PWM rectifier (BR - bidirectional rectifier).

The theoretical analysis shows the region of operation of the hybrid rectifier with improved performance. The region among the interval $0.75 \leq \alpha \leq 0.91$ minimizes the active power and the apparent power processed by the BR and maximizes the active power processed by the UR.

The advantages of this hybrid system are the capability of delivering high power levels due the parallel association of the rectifiers and cost reduction. Moreover, the increase of the reliability is another advantage by the system redundancy.

As can be seen from the experimental results, the hybrid rectifier presents near unity power factor and DC voltage regulation.

This hybrid rectifier can be applied in regenerative AC motor drives where bidirectional power flow is one of the requirements.

\section{ACKNOWLEDGMENT}

The authors would like to thank CNPq (National Council of Scientific and Technological Development) for their contribution to this work in the form of a grant provided to Carlos Henrique Illa Font (Process number 140540/2003-2).

\section{REFERENCES}

[1] A. Siebert, A. Troedson and S. Ebner, "AC to DC Power Conversion Now and in the Future", IEEE Transactions on Industry Applications, vol. 38, pp. 934-940, July/August 2002.

[2] D. A. Paice, Power Electronic Converter Harmonics Multipulse Methods for Clean Power, IEEE Press, New York, 1996.

[3] J. W. Kolar and H. Ertl, "Status of the Techniques of Three-phase Rectifier Systems with Low Effects on the Mains", in Proc. of INTELEC 1999 - International Telecommunications Energy Conference, paper 14-1, 1999.

[4] B. Singh, B. N. Singh, A. Chandra, et al, "A Review of Three-phase Improved Power Quality AC-DC Converters", IEEE Transactions on Industrial Electronics, vol. 51, pp. 641-659, June 2004.

[5] J. R. Rodríguez, J. W. Dixon, J. R. Espinoza, J. Pontt, et al, "PWM Regenerative Rectifiers: State of the Art", IEEE Transactions on Industrial Electronics, vol. 52, no. 1, pp. 5-22, February 2005.

[6] M. Baumann and J. W. Kolar, "Parallel Connection of Two Three-Phase Three-Switch Buck-Type UnityPower-Factor Rectifier Systems With DC-Link Current Balancing", IEEE Transactions on Industrial Electronics, vol. 54, no 6, pp. 3042-3053, December 2007.

[7] C. T. Pan and Y. H. Liao, "Modeling and Coordinate Control of Circulating Currents in Parallel Three-Phase Boost Rectifiers", IEEE Transactions on Industrial Electronics, vol. 54, pp. 825-838, April 2007.

[8] K. Xing, S. Mazumder, Z. Ye, F. C. Lee, et al, "The Circulating Current in Paralleled Three-phase Boost PFC Rectifiers", in Proc. of PESC 1998 - IEEE Power Electronics Specialists Conference, pp. 783-789, 1998.

[9] Z. Ye and D. Boroyevich, "A Novel Modeling and Control Approach for Parallel Three-Phase Buck Rectifiers", in Proc. of Thirty-Sixth IAS Annual Meeting Conference, vol. 1, pp. 350-356, 2001.

[10]Z. Ye, D. Boroyevich, J.-Y. Choi and F. C. Lee, "Control of Circulating Current in Two Parallel ThreePhase Boost Rectifiers", IEEE Transactions on Power Electronics, vol. 17, no 5, pp. 609-615, September 2002. 
[11] J. Rabkowski, M. Nowak, J. Matulka and R. Barlik, "Output Currents Equalization for Parallel Connected Three-phase PWM Buck Rectifiers", In Proc. of IEEE 35th Annual Power Electronics Specialists Conference, vol.4, pp. 2810-2816, 2004.

[12] M. D. Manjrekar, P. K. Steimer and T. A. Lipo, "Hybrid Multilevel Power Conversion System: a Competitive Solution for High-power Applications", IEEE Transactions on Industry Applications, vol. 36, pp. 834840, May/June 2000.

[13] Y. Sato, K. Kawamura, H. Morimoto, et al, "Hybrid PWM Rectifier to Reduce Electromagnetic Interference", In Proc. of 37th IAS Annual Meeting Industry Applications Conference, vol. 3, pp. 2141-2146, 2002.

[14] K. Mino, G. Gong and J. W. Kolar, "Novel Hybrid 12Pulse Line Interphase Transformer Boost-Type Rectifier with Controlled Output Voltage", In Proc. of The 4th International Power Electronics and Motion Control Conference-IPEMC 2004, pp. 924-931, 2004.

[15]R. L. Alves, C. H. Illa Font and I. Barbi, "Novel Unidirectional Hybrid Three-phase Rectifier System Employing Boost Topology", in Proc. of PESC 2005 The $36^{\text {th }}$ Annual IEEE Power Electronics Specialists Conference, pp. 487-493, 2005.

[16] C. H. Illa Font and I. Barbi, "A New High Power Factor Bidirectional Hybrid Three-Phase Rectifier", in Proc. of APEC 2006 - The $21^{\text {th }}$ Annual IEEE Applied Power Electronics Conference and Exposition, pp. 1300-1306, 2006.

[17] L. C. G. de Freitas, M. G. Simões, C. A. Canesin and L. C. de Freitas, "Programmable PFC Based Hybrid Multipulse Power Rectifier for Ultra Clean Power Application", IEEE Transactions on Power Electronics, vol. 21, no 4, pp. 959-966, July 2006.

[18] J. de O. Soares, C. A. Canesin, L. C. de Freitas and F. A. S. Gonçalves, "Retificador Trifásico Híbrido Operando com Controle Digital e Modulação por Histerese", Revista Eletrônica de Potência, vol. 13, no. 4, pp. 241249, Novembro de 2008.
[19] R. L. Alves and I. Barbi, "Analysis and Implementation of a Hybrid High-Power-Factor Three-Phase Unidirectional Rectifier", IEEE Transactions on Power Electronics, vol. 24, no 3, pp. 632-640, March 2009.

[20] A. V. Costa, D. B. Rodrigues, L. C. de Freitas, J. B. Vieira Jr., E. A. A. Coelho, et al, "Hybrid Three-Phase Rectifier with High Power Factor and Voltage Sags Ride-Through Capability for Utility Interface of Adjustable Speed Drives", in Proc. of COBEP 2011 - XI Brazilian Power Electronics Conference, 2011.

[21] G. Spiazzi and F. C. Lee, "Implementation of Singlephase Boost Power-factor-correction Circuits in Threephase Applications", IEEE Transactions on Industrial Electronics, vol. 44, pp. 365-371, June 1997.

\section{BIOGRAPHIES}

Carlos Henrique Illa Font was born in Erval Grande, Rio Grande do Sul, Brazil, in 1976. He received the B.Sc., M.Sc. and Ph.D. degrees in electrical engineering from Federal University of Santa Catarina, Brazil, in 2001, 2003 and 2009, respectively.

Since 2010 he is with Federal University of TechnologyParaná, Câmpus Ponta Grossa, Brazil. His interest areas include PFC converters, three-phase AC-DC converters and switching-mode power supplies for industrial applications.

Prof. Carlos is Member of IEEE Power Electronics Society, IEEE Industrial Electronics Society and Brazilian Power Electronics Society (SOBRAEP).

Ivo Barbi was born in Gaspar, Santa Catarina, Brazil, in 1949. He received the B.S. and M.S. degrees in electrical engineering from Federal University of Santa Catarina, Florianópolis, Brazil, in 1973 and 1976, respectively, and the Ph.D. degree from the Institut National Polytechnique de Toulouse, France, in 1979.

Currently he is Professor of the Power Electronics Institute (INEP) of the Federal University of Santa Catarina (UFSC).

He founded the Brazilian Power Electronics Society (SOBRAEP) and the Power Electronics Institute of the Federal University of Santa Catarina. 